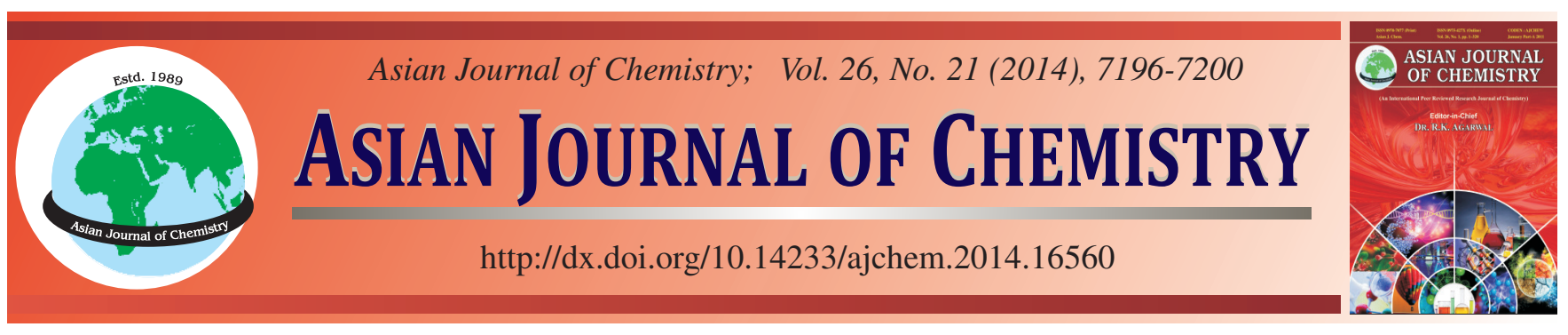

\title{
Solid Phase Extraction and Graphite Furnace Atomic Absorption Spectrometry for Determination of Silver and Palladium with Diaion SP700 as Sorbent
}

Chunhua Yang, Zhangue Huang ${ }^{*}$, Yunsong Ge and Jing Chen

Department of Chemistry, Yunnan University, Kunming 650091, P.R. China

*Corresponding author: Fax: +86 871 5032180; E-mail: zhjhuang2010@163.com; zhjhuang@ynu.edu.cn

A solid phase extraction and graphite furnace atomic absorption spectrometry (GFAAS) for the determination of silver and palladium with Diaion SP700 resin as sorbent was studied. Silver and palladium were reacted with diisopentyl sulfoxide followed by adsorption onto Diaion SP700 solid phase extraction column and $1 \mathrm{~mol} \mathrm{~L}^{-1} \mathrm{HNO}_{3}$ was used as eluent. The effects of various parameters such as acidity, flow rate of sample and eluent, type of eluent, amount of adsorbent and interfering ions have been studied. The silver and palladium in $250 \mathrm{~mL}$ solution can be concentrated to $1 \mathrm{~mL}$, representing an enrichment factor of 250 was achieved. When detected with graphite furnace atomic absorption spectrometry, the detection limits in the original samples were $0.0013 \mu \mathrm{g} \mathrm{L} \mathrm{L}^{-1}$ for $\mathrm{Ag}(\mathrm{I})$ and $0.0027 \mu \mathrm{g}$ $\mathrm{L}^{-1}$ for Pd(II). The relative standard deviations for ten replicate measurements were $3.8 \%$ for $0.2 \mu \mathrm{g} \mathrm{L}^{-1}$ silver and $3.6 \%$ for $0.2 \mu \mathrm{g} \mathrm{L}$ palladium, respectively. The presented procedure was applied to the determination of silver and palladium in biological, ore and water samples with good results (recoveries range from 94 to $106 \%$ ).

Keywords: Solid phase extraction, Silver, Palladium, Diisopentyl sulfoxide, Graphite furnace atomic absorption spectrometry.

\section{INTRODUCTION}

Silver has been recognized as a toxic element for biological systems. For human beings, silver accumulation in the body leads to a grayish blue discoloration of skin and a disturbance of the dark adaptation of eyes. Low level exposure to silver compounds is widespread owing to the use of soluble compounds to disinfect water for drinking and recreation purpose ${ }^{1-3}$. Palladium has been used in different areas of science and technology including electrical equipments, corrosion-resistant chemical wares, crucibles for high temperature reactions and catalytic chemical reaction. Palladium also enters the environment through industrial wastes because of the increasing use of palladium compounds in industry. Owing to the toxicity of palladium to mammals, fishes and aquatic organisms even at low concentrations, the serious environmental problems may occur ${ }^{4}$.

The most widely used methods for determination of silver and palladium in environmental samples include electrothermal atomic absorption spectrometry (ETAAS), graphite furnace atomic absorption spectrometry (GFAAS), inductively coupled plasma atomic emission spectrometry (ICP-AES) and spectrophotometric methods ${ }^{5-11}$. However, the determination of silver and palladium in environmental samples by spectrometric techniques is strongly hampered by numerous spectral and non-spectral interferences arising from a complicated sample matrix.
In environmental samples, the low concentration of silver and palladium (ng mL $\mathrm{m}^{-1}$ levels) together with the high concentration of interfering matrix components often requires an enrichment step combined with a matrix separation. Several methods have been reported for the separation and preconcentration of silver and palladium, such as dispersive liquid-liquid microextraction extraction (DLLME), cloud point extraction (CPE), high-performance liquid chromatography (HPLC) and solid-phase extraction (SPE) ${ }^{12-19}$. Among these techniques, solid-phase extraction is one of the most important preconcentration methodologies because of its advantages of high enrichment factor, high recovery, rapid phase separation, low cost, low consumption of organic solvents and the ability to combine with different detection techniques by on-line or offline mode.

The aim of this work is to combine solid-phase extraction with graphite furnace atomic absorption spectrometry (GFAAS) and develop a new method for the determination of silver and palladium. In this method diisopentyl sulfoxide (DISO), reacts with silver and palladium forming a stable metal-diisopentyl sulfoxide chelates. Subsequently, water sample containing metal-diisopentyl sulfoxide chelates was passed through Diaion SP700 cartridge. The metal-diisopentyl sulfoxide chelates were preconcentrated on a nonpolar resin Diaion SP700. The metal-diisopentyl sulfoxide chelates adsorbed on Diaion SP700 cartridge was eluted with $\mathrm{HNO}_{3}$. The levels 
of analyte ions in the samples were determined by the graphite furnace atomic absorption spectrometry. The optimum analytical conditions for the quantitative recoveries of silver and palladium on Diaion SP700 adsorption resin were investigated.

\section{EXPERIMENTAL}

A Z-2000 polarized zeeman atomic absorption spectrophotometer (Hitachi High- Technologies Corpotation, Japan) was used in the studies. Hitachi hollow cathode lamps (HCL) were used for the determination of $\mathrm{Ag}(328.1 \mathrm{~nm})$ and Pd (247.6 nm). High-purity argon (99.999\%, Messer Chemical Corpotation, Kunming, China) was used as the purge and sheath gas throughout at a flow rate of $30 \mathrm{~mL} \mathrm{~min}^{-1}$. The output signals were collected and processed with peak-height mode. Other operating conditions were carried out according recommendations of manufacturer.

A peristaltic pump mode FIA-3110 (Titan Instruments Co., Ltd. Beijing, China) was used in the solid phase extraction process. A WX-4000 closed vessel microwave system (Preekem Scientific Instruments Co., Ltd. Shanghai, China. maximum pressure $35 \mathrm{~atm}$, maximum temperature $235^{\circ} \mathrm{C}$ ).

The certified standard reference materials (ore GBW07290 and biological GBW07603) were obtained from Chinese Standards Center (Beijing, China). Working standard solutions were obtained by appropriate dilution of the stock standard solution.

$0.5 \%(\mathrm{w} / \mathrm{v})$ solution of diisopentyl sulfoxide was prepared by dissolving appropriate amount of diisopentyl sulfoxide in ethanol. Ultra-pure water was used throughout. All the glass wares used in the experiments were kept in $10 \%$ nitric acid for at least $24 \mathrm{~h}$ and subsequently washed four times with ultrapure water. All other reagents used were of the highest available purity and of at least analytical reagent grade. Ultra-pure water of resistivity $18 \mathrm{M} \Omega \mathrm{cm}$ obtained from a UPHW purification device (Ulupure Co. Shanghai, China) was used to prepare all the solutions.

Diisopentyl sulfoxide was obtained from Yunnan Gold Group Co. Diaion SP700 was purchased from Mitsubishi Chemical Corporation (Tokyo, Japan). Diaion SP700 resin is an aromatic type adsorbent. It is based on crosslinked polystyrenic matrix. Its surface area is $1200 \mathrm{~m}^{2} \mathrm{~g}^{-1}$. It was washed successively with methanol, water, $1 \mathrm{~mol} \mathrm{~L}^{-1} \mathrm{HNO}_{3}$ in acetone, water, $1 \mathrm{~mol} \mathrm{~L}^{-1} \mathrm{NaOH}$ and water, sequentially.

Preconcentration procedure: An off-line column procedure was applied for the preconcentration process. The Teflon column was $3 \mathrm{~cm}$ long and $1 \mathrm{~cm}$ in diameter. The $2 \mu \mathrm{m}$ of sieve plate was placed to prevent loss of the resin beads during sample loading. Then, $800 \mathrm{mg}$ of Diaion SP700 resin was poured into the column. The resin bed was washed with plenty of ultra-pure water until neutral $\mathrm{pH}$ and subsequently reused. The method was tested with model solutions before its application to real samples. $250 \mathrm{~mL}$ of solutions containing 1-80 ng of analyte ions, $5 \mathrm{~mL}$ of $12 \mathrm{~mol} \mathrm{~L}^{-1}$ hydrochloric acid solution and $8 \mathrm{~mL}$ of $0.5 \%$ diisopentyl sulfoxide was passed through the column at a flow rate of $10 \mathrm{~mL} \mathrm{~min}^{-1}$ using a vacuum aspirator. The retained silver and palladium ions were eluted from the column by $1 \mathrm{~mL}$ of $1 \mathrm{~mol} \mathrm{~L}^{-1} \mathrm{HNO}_{3}$ and the concentrations of silver and palladium ions were determined by GFAAS. A blank solution was also run under the same conditions without adding the analyte ions.

Sample preparation: The developed method has been successfully applied to the determination of silver and palladium ions in the certified standard reference materials (ore GBW07290 and biological GBW07603).

For ore reference materials samples, the $10 \mathrm{~g}$ of ore reference materials were transferred into a porcelain crucible and roasted for $1.5 \mathrm{~h}$ in a muffle furnace at $610^{\circ} \mathrm{C}$. After roasting, the sample was transferred to $400 \mathrm{~mL}$ glass beaker and $80 \mathrm{~mL}$ of freshly prepared aqua regia was added to sample. $1 \mathrm{~g}$ of $\mathrm{NaCl}$ was added to stabilize the analyte ions chloride complex during evaporation on a hot plate. The beaker was covered with a watch glass and heated on a hot plate. Heating was continued for at least $3 \mathrm{~h}$ and enough aqua regia was added at regular intervals to maintain the free acid level at about $1 \mathrm{~cm}$ above the sample level. The watch glass was removed and the content was evaporated slowly until the residue became nearly dry. Then, $30 \mathrm{~mL}$ of $6 \mathrm{~mol} \mathrm{~L}^{-1} \mathrm{HCl}$ was added to the beaker and the solution was warmed until clear solution was obtained. Afterwards, sample solution was cooled and filtered using whatman No.1 filter paper (pore size, $11 \mu \mathrm{m}$ ). The residue was washed with minimum amounts of $0.1 \mathrm{~mol} \mathrm{~L}^{-1} \mathrm{HCl}$. The final residue was discarded and the filtrate was then dissolved and diluted to $100 \mathrm{~mL}$ with distilled water. Finally, analyte ions in ore sample were determined by the proposed method.

For biological samples, the sample was mixed with concentrated nitric acid and $30 \%$ hydrogen peroxide in microwave digestion system. The bombs were sealed tightly and then positioned in the carousel of the microwave oven. Digestion conditions for microwave system of the samples were applied as $5 \mathrm{~min}$ for $400 \mathrm{~W}$. Blanks were prepared in the same way as the sample. After cooling, the preconcentration procedure given above was applied.

For water samples, the samples were immediately acidified by adding several drops of nitric acid and filtrated with $0.45 \mu \mathrm{m}$ filter. Then the preconcentration procedure given above was applied to the samples. River water sample was collected from Xiaoqing river (Dongchuang, P.R. China). Lake water sample was collected from Qilu lake (Yuxi, P.R. China). Tap water sample was freshly collected from our laboratory.

GFAAS analysis: The GFAAS analysis condition is listed in Table-1. For samples analysis, a $20 \mu \mathrm{L}$ aliquot of the samples or standard solution was injected into the graphite cuvette for the GFAAS determination. The atomic absorption signals were measured with the Zeeman background corrector in operation. The measurement was repeated three times and the obtained signals were averaged.

\section{RESULTS AND DISCUSSION}

Effect of acidity: The acidity of the sample solution is one of the important factors for quantitative recoveries of the analyte ions. According to the results (Fig. 1), quantitative recoveries $(>95 \%)$ for analyte ions were obtained in the presence of $\mathrm{HCl}$ in the concentration range: $0.1-0.5 \mathrm{~mol} \mathrm{~L}^{-1}$. Thus $5 \mathrm{~mL} 12 \mathrm{~mol} \mathrm{~L}^{-1} \mathrm{HCl}$ solutions was recommended to control acidity. 
TABLE-1

SETTING OF ANALYTICAL CONDITIONS

\begin{tabular}{lll}
\hline \multicolumn{1}{c}{ Analytical condition } & \multicolumn{1}{c}{$\mathrm{Ag}$} & \multicolumn{1}{c}{$\mathrm{Pd}$} \\
\hline Calculation mode & Peak height & Peak height \\
Wavelength $(\mathrm{nm})$ & 328.1 & 247.6 \\
Slit width $(\mathrm{nm})$ & 1.3 & 0.4 \\
Time constant $(\mathrm{s})$ & 0.1 & 0.1 \\
Lamp current $(\mathrm{mA})$ & $7 \mathrm{~mA}$ & $10 \mathrm{~mA}$ \\
Cuvette type & Pyro tube HR & Pyro tube HR \\
Dry start/end temp. $\left({ }^{\circ} \mathrm{C}\right)$ & $80 / 140$ & $80 / 140$ \\
Dry ramp time $(\mathrm{S})$ & 40 & 40 \\
Ash start/end temp. $\left({ }^{\circ} \mathrm{C}\right)$ & $500 / 500$ & $700 / 700$ \\
Ash ramp time $(\mathrm{S})$ & 20 & 20 \\
Atomize start/end temp. $\left({ }^{\circ} \mathrm{C}\right)$ & $2200 / 2200$ & $2400 / 2400$ \\
Atomize hold time $(\mathrm{S})$ & 5 & 5 \\
Clean start/end temp. $\left({ }^{\circ} \mathrm{C}\right)$ & $2500 / 2500$ & $2500 / 2500$ \\
Clean hold time $(\mathrm{S})$ & 4 & 4 \\
Gas flow $\left(\mathrm{mL}\right.$ min $\left.{ }^{-1}\right)$ & 30 & 30 \\
Sample injection volume $(\mu \mathrm{L})$ & 20 & 20 \\
\hline
\end{tabular}

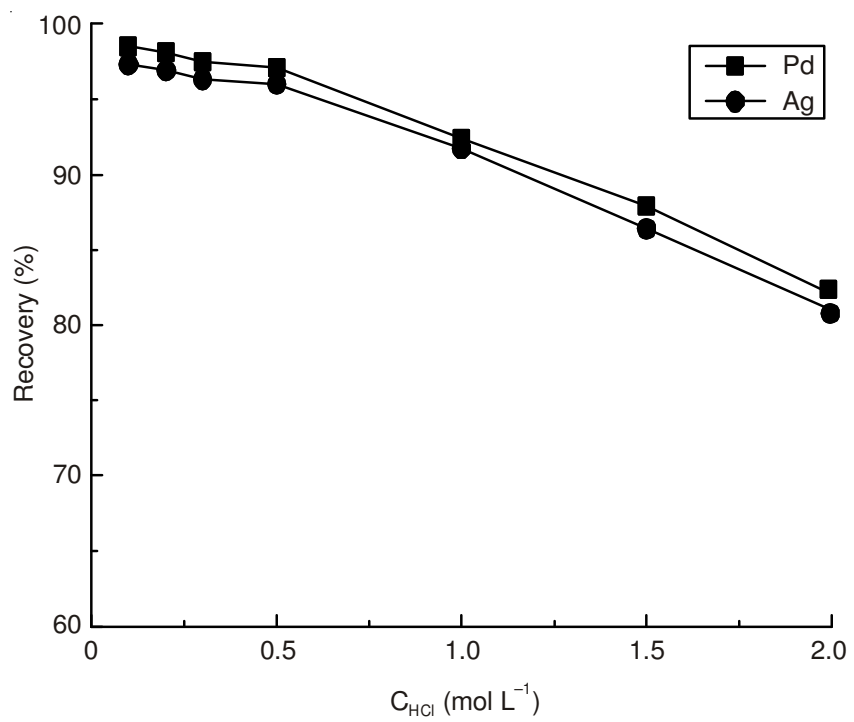

Fig. 1. Influences of acidity on the recovery of silver and palladium. Conditions: Sample volume: $250 \mathrm{~mL}$; flow rate: $10 \mathrm{~mL} \mathrm{~min}^{-1}$; amount of the resin: $800 \mathrm{mg}$

Influences of diisopentyl sulfoxide amount: In order to determine the amounts of diisopentyl sulfoxide required for quantitative recovery for silver and palladium, the proposed method was applied. Changing the diisopentyl sulfoxide amounts $(0.5 \%$ solution $)$ at the range of $1-10 \mathrm{~mL}$. The results showed that the recovery values of silver and palladium were increased with increasing amounts of diisopentyl sulfoxide added. The recovery reaches a constant value with at least $5 \mathrm{~mL}$ of $0.5 \%$ diisopentyl sulfoxide solution used. On this basis, studies were carried out at $8 \mathrm{~mL}$ of diisopentyl sulfoxide. This amount of diisopentyl sulfoxide is enough for the separation and preconcentration procedure because of the very low level of the investigated silver and palladium concentrations in real samples.

Effects of amount of resin: Also the amounts of solid phase extraction material are another important factor on the column studies for the quantitative recoveries of metaldiisopentyl sulfoxide chelates. The effect of the amount of Diaion SP700 on the sorption of metal ions was examined in the range of $300-1000 \mathrm{mg}$. The results demonstrated that, quantitative recoveries ( $>95 \%$ ) of silver and palladium were observed in the range of $600-900 \mathrm{mg}$. Above $900 \mathrm{mg}$ the recoveries were below $95 \%$ with $1 \mathrm{~mL}$ of the eluent. Therefore, in the proposed procedure, $800 \mathrm{mg}$ of Diaion SP700 resin is recommended.

Effect of flow rate of sample solution and eluent: The influence of flow rate on the adsorption of metal-diisopentyl sulfoxide chelates was also studied. Flow rate in the range of 8-12 $\mathrm{mL} \mathrm{min}^{-1}$ had no significant effect on the recoveries of silver and palladium. Therefore, in the proposed procedure, $10 \mathrm{~mL} \mathrm{~min}^{-1}$ flow rate is recommended.

Among several media investigated as eluent (e.g., $\mathrm{H}_{2} \mathrm{O}$, $\mathrm{HNO}_{3}$, ethanol, methanol, acetone, $\mathrm{NH}_{3}$ and thiourea), only $\mathrm{HNO}_{3}$ showed satisfactory elution characteristics. $1 \mathrm{~mL}$ of 1 mol L-1 $\mathrm{HNO}_{3}$ provided quantitative recovery (> $95 \%$ ) and reproducibility. The elution was performed in the opposite direction to avoid the clogging of the column.

The flow rate of eluent solution was examined in the range of 0.5-2 $\mathrm{mL} \mathrm{min}^{-1}$. Maximum recoveries for the analyte ions were obtained in the range of $0.5-1 \mathrm{~mL} \mathrm{~min}^{-1}$. The flow rate of $1 \mathrm{~mL} \mathrm{~min}^{-1}$ was chosen as optimum value.

Effect of sample volume: The effect of the sample solution volume on the metal sorption on Diaion SP700 was studied by passing 50-500 mL volumes through Diaion SP700 column at a $10 \mathrm{~mL} \mathrm{~min}{ }^{-1}$ flow rate. The results were given in Fig. 2. The adsorption of the metal ions was not affected by sample volume when the volume is below $250 \mathrm{~mL}$. However, the percent of analytes sorption decrease when the volume is above $250 \mathrm{~mL}$. The recoveries of analytes decrease probably due to the excess analytes loaded over the column capacity with increasing sample volume above $250 \mathrm{~mL}$. The adsorbed metals can be eluted with $1 \mathrm{~mL}$ of $1 \mathrm{~mol} \mathrm{~L}^{-1} \mathrm{HNO}_{3}$ representing an enrichment factor of 250 was achieved by this technique.

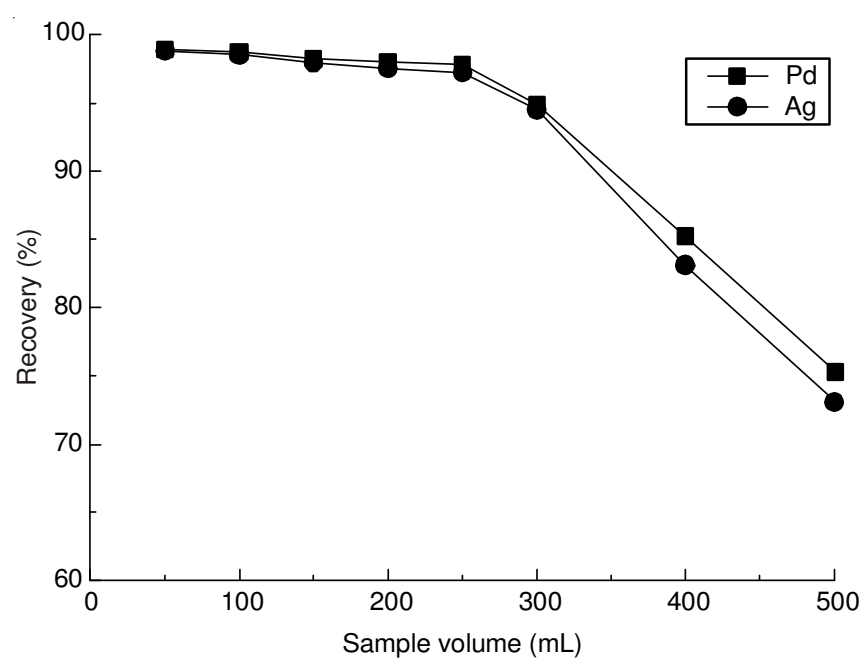

Fig. 2. Effect of the sample volume on the recoveries of silver and palladium. Conditions: $\mathrm{HCl}$ in the concentration range: $0.1-0.5 \mathrm{~mol}$ $\mathrm{L}^{-1}$; flow rate: $10 \mathrm{~mL} \mathrm{~min}^{-1}$; amount of the resin: $800 \mathrm{mg}$

Effect of interfering ions on recovery: In order to evaluate the possibility of selective recovery of silver and palladium ions in the presence of alkaline, earth alkaline metals and major anions of the real samples, the procedure has been performed with $250 \mathrm{~mL}$ solutions containing such ions. Quantitative 
recoveries $\left(>95 \%\right.$ ) for $1500 \mathrm{mg} \mathrm{L}^{-1}$ of $\mathrm{NaCl}$, for $800 \mathrm{mgL}^{-1}$ of $\mathrm{Ca}^{2+}$, for $600 \mathrm{mg} \mathrm{L}^{-1}$ of $\mathrm{K}^{+}, \mathrm{Fe}^{3+}, 300 \mathrm{mg} \mathrm{L}^{-1}$ for $\mathrm{Zn}^{2+}, \mathrm{Cu}^{2+}, 100$ $\mathrm{mg} \mathrm{L}^{-1}$ for $\mathrm{Al}^{3+}, \mathrm{Ni}^{2+}$ were obtained. These tolerable levels of foreign ions were enough for the quantitative separation of silver and palladium ions from the matrix of the real samples.

Loading capacity: In order to study the adsorptive capacity of Diaion SP700 resin, batch method was used. To $0.1 \mathrm{~g}$ Diaion SP700 resin was placed in the conical flasks. Stock solution of $\operatorname{Ag}(\mathrm{I})$ and $\mathrm{Pd}(\mathrm{II})$ were added to the flask, respectively. Acidity of the solution was adjusted to $0.1-0.5 \mathrm{~mol} \mathrm{~L}^{-1}$ using $12 \mathrm{~mol} \mathrm{~L}^{-1} \mathrm{HCl}$ solution. After shaking for $3 \mathrm{~h}$, the mixture was filtered. Concentration of silver and palladium ions were measured by GFAAS. The loading capacity of Diaion SP700 was $17 \mathrm{mg} \mathrm{g}^{-1}$ for $\mathrm{Ag}(\mathrm{I})$ and $11 \mathrm{mg} \mathrm{g}^{-1}$ for Pd(II), respectively.

Calibration curve and detection limit: Using the optimized conditions of preconcentration, calibration curve was prepared for $\mathrm{Ag}(\mathrm{I})$ and $\mathrm{Pd}(\mathrm{II})$. The limit of detection(LOD) value (blank $+3 \mathrm{~s}$ ) were found to be $0.0013 \mu \mathrm{g} \mathrm{L} \mathrm{L}^{-1}$ for $\mathrm{Ag}(\mathrm{I})$ and $0.0027 \mu \mathrm{g} \mathrm{L}^{-1}$ for $\mathrm{Pd}(\mathrm{II})$, respectively. The results were also shown in Table-2. Diaion SP700 resin can be reused at least 50 times.

\begin{tabular}{|c|c|c|}
\hline \multicolumn{3}{|c|}{$\begin{array}{c}\text { TABLE-2 } \\
\text { ANALYTICAL CHARACTERISTICS } \\
\text { OF THE PROPOSED METHOD }\end{array}$} \\
\hline \multirow{2}{*}{ Parameter } & \multicolumn{2}{|c|}{ Analytical feature } \\
\hline & Palladium & Silver \\
\hline $\begin{array}{l}\text { Regression equation (C in } \mu \mathrm{g} \\
\left.\mathrm{L}^{-1}\right)^{\mathrm{a}}\end{array}$ & $\begin{array}{l}\mathrm{A}=5.16 \times 10^{-3} \\
\mathrm{C}+2.16 \times 10^{-3}\end{array}$ & $\begin{array}{l}\mathrm{A}=9.85 \times 10^{-3} \\
\mathrm{C}+1.86 \times 10^{-3}\end{array}$ \\
\hline Linear range $\left(\mu \mathrm{g} \mathrm{L}^{-1}\right)^{\mathrm{a}}$ & $2-80$ & $1-70$ \\
\hline Correlation coefficient & 0.9994 & 0.9993 \\
\hline Enrichment factor & 250 & 250 \\
\hline $\begin{array}{l}\text { The relative standard } \\
\text { deviation }\end{array}$ & $\begin{array}{l}3.6\left(0.2 \mu \mathrm{g} \mathrm{L}{ }^{-1},\right. \\
\mathrm{n}=10)^{\mathrm{b}}\end{array}$ & $\begin{array}{l}3.8\left(0.2 \mu \mathrm{g} \mathrm{L} \mathrm{L}^{-1}\right. \\
\mathrm{n}=10)^{\mathrm{b}}\end{array}$ \\
\hline $\begin{array}{l}\text { Detection limit }\left(\mu \mathrm{g} \mathrm{L}^{-1}\right)^{\mathrm{b}} \\
(\mathrm{LOD}=\text { bland }+3 \sigma, \mathrm{n}=12)\end{array}$ & 0.0027 & 0.0013 \\
\hline $\begin{array}{l}\text { Quantification limit }\left(\mu \mathrm{g} \mathrm{L}^{-1}\right)^{\mathrm{b}} \\
(\mathrm{LOQ}=\text { bland }+10 \sigma, \mathrm{n}=12)\end{array}$ & 0.008 & 0.004 \\
\hline
\end{tabular}

Applications of the presented procedure: In order to establish the validity of the proposed procedure, the method has been applied to the determination of silver and palladium in the certified standard reference materials samples (GBW07290 and GBW07603). The results were given in Table-3.

\begin{tabular}{|c|c|c|}
\hline \multicolumn{3}{|c|}{$\begin{array}{c}\text { TABLE-3 } \\
\text { DETERMINATION OF SILVER AND PALLADIUM } \\
\left(\mathrm{ng} \mathrm{g}^{-1}\right) \text { IN THE CERTIFIED REFERENCE MATERIALS AFTER } \\
\text { APPLICATION OF THE PRESENTED PROCEDURE }(\mathrm{n}=5)\end{array}$} \\
\hline Sample & Certified value $\left(\mathrm{ng} \mathrm{g}^{-1}\right)$ & Our value $\left(\mathrm{ng} \mathrm{g}^{-1}\right)$ \\
\hline GBW07603 & $\operatorname{Ag}(49 \pm 7)$ & $\operatorname{Ag}(48 \pm 9)$ \\
\hline GBW07290 & $\operatorname{Pd}(4.6 \pm 0.6)$ & $\operatorname{Pd}(4.5 \pm 0.7)$ \\
\hline
\end{tabular}

The proposed method was applied to determine silver and palladium in the water samples. The results for the water samples were given in Table-4. The results indicate that the recoveries of silver and palladium ions were in the range of 94-106\%.

\begin{tabular}{ccccccc}
\multicolumn{7}{c}{ TABLE-4 } \\
DETERMINATION OF SILVER AND \\
PALLADIUM $\left(\mu \mathrm{g} \mathrm{L}^{-1}\right)$ IN WATER SAMPLES $(\mathrm{n}=5)$ \\
\hline \multirow{3}{*}{ Samples } & \multicolumn{7}{c}{ Added } & \multicolumn{3}{c}{ Found $^{\mathrm{a}}$ by present } \\
method & \multicolumn{2}{c}{ Recovery $(\%)$} \\
\cline { 2 - 8 } & $\mathrm{Ag}$ & $\mathrm{Pd}$ & $\mathrm{Ag}$ & $\mathrm{Pd}$ & $\mathrm{Ag}$ & $\mathrm{Pd}$ \\
\hline \multirow{2}{*}{ Lake water } & 0 & 0 & $0.8 \pm 0.1$ & $\mathrm{BDL}$ & - & - \\
& 5 & 5 & $5.7 \pm 0.2$ & $5.1 \pm 0.1$ & $98 \pm 4$ & $102 \pm 2$ \\
& 10 & 10 & $10.9 \pm 0.3$ & $9.6 \pm 0.2$ & $101 \pm 3$ & $96 \pm 2$ \\
\hline \multirow{3}{*}{ Tap water } & 0 & 0 & $\mathrm{BDL}$ & $\mathrm{BDL}$ & - & - \\
& 5 & 5 & $5.2 \pm 0.1$ & $4.9 \pm 0.2$ & $104 \pm 2$ & $98 \pm 4$ \\
& 10 & 10 & $10.2 \pm 0.3$ & $9.9 \pm 0.5$ & $102 \pm 3$ & $99 \pm 5$ \\
\hline \multirow{3}{*}{ River water } & 0 & 0 & $0.6 \pm 0.1$ & $0.9 \pm 0.1$ & - & - \\
& 5 & 5 & $5.5 \pm 0.2$ & $6.0 \pm 0.2$ & $98 \pm 4$ & $102 \pm 4$ \\
& 10 & 10 & $10.8 \pm 0.4$ & $11.3 \pm 0.2$ & $102 \pm 4$ & $104 \pm 2$ \\
\hline
\end{tabular}

-Not determined; ${ }^{\mathrm{a} M e a n} \pm$ S.D.

Table-5 compares the characteristic data of the proposed method with other preconcentration methods for silver and palladium reported in literatures. Generally, the detection limit and enhancement factor obtained by the present method are comparable to those reported methods and the enrichment factor has been greatly improved.

\begin{tabular}{|c|c|c|c|c|c|}
\hline \multicolumn{6}{|c|}{$\begin{array}{l}\text { TABLE-5 } \\
\text { COMPARISON OF THE PRESENT } \\
\text { METHOD WITH OTHER SYSTEM }\end{array}$} \\
\hline $\begin{array}{l}\text { Enrichment } \\
\text { method }\end{array}$ & $\begin{array}{c}\text { Detection } \\
\text { Method }\end{array}$ & $\begin{array}{c}\text { Metal } \\
\text { ions }\end{array}$ & $\begin{array}{l}\text { Limit of } \\
\text { detection } \\
\left(\mathrm{ng} \mathrm{L}^{-1}\right)\end{array}$ & $\begin{array}{l}\text { Enrichment } \\
\text { factor }\end{array}$ & Ref. \\
\hline DLLME & GFAAS & $\mathrm{Ag}$ & 12 & 132 & 3 \\
\hline DLLME & GFAAS & $\mathrm{Ag}$ & 20 & 72 & 5 \\
\hline CPE & ETAAS & $\mathrm{Ag}$ & 12 & 60 & 7 \\
\hline SPE & FAAS & $\begin{array}{l}\mathrm{Ag}, \\
\mathrm{Pd}\end{array}$ & $\begin{array}{c}\operatorname{Ag}(1800), \\
\operatorname{Pd}(4200)\end{array}$ & 110 & 4 \\
\hline DLLME & GFAAS & $\mathrm{Pd}$ & 2.4 & 156 & 8 \\
\hline SPE & GFAAS & $\mathrm{Pd}$ & 2000 & 8.7 & 9 \\
\hline SPE & ICP-AES & $\mathrm{Pd}$ & 0.2 & 100 & 10 \\
\hline $\mathrm{CPE}$ & Spectrophotometry & $\mathrm{Pd}$ & 0.47 & 50 & 11 \\
\hline SPE & GFAAS & $\begin{array}{l}\mathrm{Ag}, \\
\mathrm{Pd}\end{array}$ & $\operatorname{Ag}(1.3), \operatorname{Pd}(2.7)$ & 250 & $\begin{array}{l}\text { This } \\
\text { work }\end{array}$ \\
\hline
\end{tabular}

\section{Conclusion}

The described method using the Diaion SP700 resin combined with diisopentyl sulfoxide has a good potential for the enrichment and separation of silver and palladium ions from the biological samples, ore and water samples and their determinations by GFAAS. The method is a simple, sensitive, precise, reliable and accurate technique. Instead of the use of fresh solvent as an extracting phase for each sample, the reusability of Diaion SP700 was greater than 50 cycles without any loss in its sorption behaviour. The elution was easily performed with $1 \mathrm{~mol} \mathrm{~L}^{-1} \mathrm{HNO}_{3}$ and the metal ions in $250 \mathrm{~mL}$ solution can be concentrated to $1 \mathrm{~mL}$, representing an enrichment factor of 250 was achieved. The tolerance limits of interfering ions on the recovery of silver and palladium ions are quite high. The results acquired from the analyses of the two standard reference materials confirmed the reliability of the method. The proposed method possesses lower limit of detection. Enrichment factor are superior to those reported methods. The matrix effects with the method were reasonably tolerable, which makes it suitable for the determination of trace amount of silver and palladium ions in environmental samples. 


\section{ACKNOWLEDGEMENTS}

This work was supported by the National Natural Science Foundation of China (51264038), Key Natural Science Foundation of China (U0937601), Development Program of China (2011AA03A405D) and Science and Technology Support Program of China (2008BAB32B10).

\section{REFERENCES}

1. R.G.O. Araujo, F. Vignola, I.N.B. Castilho, B. Welz, M.G.R. Vale, P Smichowski, S.L.C. Ferreira and H. Becker-Ross, Microchem. J., 109, 36 (2013).

2. S. Saeki, M. Kubota and T. Asami, Water Air Soil Pollut., 83, 253 (1995).

3. P. Liang and L.L. Peng, Mikrochim. Acta, 168, 45 (2010).

4. G. Khayatian and S. Hassanpoor, J. Incl. Phenom. Macrocycl. Chem., 73, 151 (2012)

5. P. Liang, L.L. Zhang and E. Zhao, Talanta, 82, 993 (2010).
6. I. López-García, Spectrochim. Acta B, 58, 1715 (2003).

7. J.L. Manzoori, H. Abdolmohammad-Zadeh and M. Amjadi, J. Hazard. Mater., 144, 458 (2007).

8. P. Liang, E. Zhao and F. Li, Talanta, 77, 1854 (2009).

9. C.B. Ojeda, F. Sánchez Rojas and J.M.C. Pavón, Mikrochim. Acta, 158, 103 (2007).

10. M.R. Jamali, Y. Assadi, F. Shemirani and M. Salavati-Niasari, Talanta, 71, 1524 (2007).

11. F. Shemirani, R.R. Kozani, M. Reza Jamali, Y. Assadi and M.-R. Milani Hosseini, Int. J. Environ. Anal. Chem., 86, 1105 (2006).

12. M. Soylak and M. Tuzen, J. Hazard. Mater., 152, 656 (2008).

13. A.N. Anthemidis, D.G. Themelis and J.A. Stratis, Talanta, 54, 37 (2001).

14. R.S. Praveen, S. Daniel, T.P. Rao, S. Sampath and K.S. Rao, Talanta, 70, 437 (2006).

15. C.T. Camagong and T. Honjo, Anal. Bioanal. Chem., 373, 856 (2002).

16. M. Tuzen and M. Soylak, J. Hazard. Mater., 164, 1428 (2009).

17. C.K. Christou and A.N. Anthemidis, Talanta, 78, 144 (2009).

18. F. Shemirani, R.R. Kozani and Y. Assadi, Mikrochim. Acta, 157, 81 (2007).

19. S.Z. Mohammadi, D. Afzali, M.A. Taher and Y.M. Baghelani, Talanta, 80, 875 (2009). 